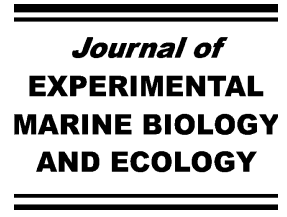

Journal of Experimental Marine Biology and Ecology 318 (2005) 191-199

www.elsevier.com/locate/jembe

\title{
Impact of microphallid trematodes on the survivorship, growth, and reproduction of an isopod (Cyathura carinata)
}

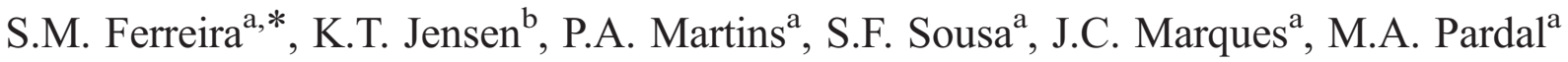 \\ a IMAR —Institute of Marine Research, Department of Zoology, University of Coimbra, 3004-517 Coimbra, Portugal \\ ${ }^{\mathrm{b}}$ Department of Marine Ecology, Institute of Biological Sciences, University of Aarhus, Finlandsgade 14, DK-8200 Aarhus N, Denmark
}

Received 23 June 2004; received in revised form 17 December 2004; accepted 18 December 2004

\begin{abstract}
Crustaceans are second intermediate hosts to several microphallid species (Trematoda). Some of these parasites are potentially pathogenic or manipulative. A laboratory experiment was performed to assess the impact of microphallids on the survival, growth and fecundity of Cyathura carinata, a protogynous hermaphroditic isopod, widespread within European estuaries. For nearly 12 weeks, experimental populations of infected and non-infected isopods were kept at $25^{\circ}$ C. C. carinata carrying microphallid cysts showed higher mortality rates than non-infected specimens and were not able to produce embryos. The reduced fecundity of infected isopods could be caused by parasite-induced castration and/or by mating failure due to behavioural modifications in one of the sexes. It might also be associated with lower growth rates and lower moulting frequencies, since infected C. carinata were significantly smaller than the non-infected after 9 weeks. This may imply a setback for the isopods to achieve sexual maturity (which may also affect the population sex ratio) and for females to lay their eggs in the marsupia. Regardless of the mechanisms involved, microphallids may have severe consequences for their host populations, through negative effects on survival, growth and fecundity. For species with direct development, such as $C$. carinata, parasite-induced reproduction failure may contribute to temporal fluctuations of abundance. Based on the present results, it is recommended to include parasites as an important factor influencing host populations from shallow-water ecosystems.
\end{abstract}

(C) 2005 Elsevier B.V. All rights reserved.

Keywords: Fecundity; Growth; Isopod; Microphallid; Mortality; Parasite

\section{Introduction}

Amphipods and isopods from shallow-water ecosystems are hosts to a variety of trematode species.

* Corresponding author. Tel.: +351 239836386; fax: +351 These parasites are potentially pathogenic or manip239823603.

E-mail address: smff@ci.uc.pt (S.M. Ferreira). ulative and thus may influence the population dynamics of their hosts (Helluy, 1984; Thomas et

0022-0981/\$ - see front matter (C) 2005 Elsevier B.V. All rights reserved. doi:10.1016/j.jembe.2004.12.018 
al., 1995; Mouritsen and Jensen, 1997; Meissner and Bick, 1999). At least 10 species of microphallid trematodes using mud snails Hydrobia spp. (first intermediate hosts) are represented in benthic peracarid crustaceans from the north-western European estuaries and coastal lagoons (Deblock, 1980). By using crustaceans as their second intermediate hosts, the parasites are capitalising on existing prey-predator relationships to reach water birds, their definitive hosts. Reported effects of microphallids on crustaceans include enhanced host mortality (Mouritsen and Jensen, 1997; Jensen et al., 1998; Meissner and Bick, 1999), behavioural control to promote transmission to the definitive host (Helluy, 1984; Combes, 2001), reduced offspring production and prolonged intermoult stages (Muus, 1967; Thomas et al., 1995, 1996a,b). Microphallid species exhibit a variety of life histories and each of them may have different effects in different host species, reflecting the individual parasite-host evolution. This makes it rather unpredictable whether microphallids are harmless, manipulative, or pathogenic.

Recognizing the possible effects of microphallid trematodes in crustaceans, it is necessary to consider these in population studies of host organisms. The mud snail Hydrobia ulvae and the isopod Cyathura carinata are two widely distributed macrozoobenthic species in European brackish water ecosystems. These two macroinvertebrates co-occur in the Mondego Estuary (western Portugal) and both are infected with different larval stages of the same microphallid species (Jensen et al., 2004). Up to $90 \%$ of $C$. carinata from a Zostera noltii meadow were infected by these trematodes, with a maximum mean intensity of 12 cysts (Jensen et al., 2004). Descriptive data suggest that microphallids control the reproductive success of the isopod, as ovigerous females were considerably underrepresented among infected individuals (Jensen et al., 2004). At the Mondego estuary, C. carinata has a life span of 2 years, shows continuous growth rates, and generates a single cohort per year (Ferreira et al., 2004). To understand the importance of microphallid parasites for the population dynamics of this isopod, a laboratory experiment was conducted to study the survivorship, growth and fecundity of non-infected and infected specimens. As C. carinata is a protogynous hermaphrodite (1-yearold females may endure sex reversal and reproduce as males in the second year), microphallids could also potentially influence sex ratio and male differentiation of the isopod. Possible mechanisms explaining the complex of effects caused by microphallid infections are discussed, as well as their consequences for the population dynamics of $C$. carinata.

\section{Materials and methods}

\subsection{Collection and treatment of experimental ani- mals, sediment and water}

C. carinata specimens were collected from two different sites of the Mondego Estuary $\left(40^{\circ} 08^{\prime} \mathrm{N}\right.$, $8^{\circ} 50^{\prime} \mathrm{W}$ ), at the end of January of 2003 . One of the sites is a sand flat, located in an inner area of the estuary, where the isopods are abundant and almost non-infected (Jensen et al., 2004). The other site is a $Z$. noltii meadow, situated $600 \mathrm{~m}$ downstream of the previous area, where C. carinata are scarce and usually infected by microphallids (Jensen et al., 2004). All individuals used in the experiment belonged to the same population since the isopods (especially juveniles) generally colonise the Z. noltii meadow, after the reproduction season (Ferreira et al., 2004). Sediment containing burrowed $C$. carinata was collected with a hand corer and sieved in estuarine water, through a $0.5 \mathrm{~mm}$ mesh. The isopods retained were sorted in situ, until achieving 500 specimens from each site. The captured organisms were transported to laboratory and kept at $25^{\circ} \mathrm{C}$. Each C. carinata was inspected for the presence of cysts under a stereomicroscope. Infected specimens were separated from the others. Most of them had only 1 cyst, which was much lower than the intensity observed in the natural population, in previous years (Jensen et al., 2004). To enhance the parasite load, the infected isopods were immediately incubated in a container for $24 \mathrm{~h}$, together with infected H. ulvae. Maritrema subdolum, Microphallus claviformis and one until now undescribed Levinseniella sp. were the microphallid species used, being the only ones so far identified in the Mondego Estuary (Jensen et al., 2004). The cysts from the first 2 species have more or less the same size $(\approx 170 \mu \mathrm{m}$ diameter; Deblock, 1980) and cannot be distinguished from each other when inside living hosts. Still, both are very different 
from the third one, whose cysts are very large $(\approx 340$ $\mu \mathrm{m}$ diameter; Jensen et al., 2004). The maturation of these cysts may last between 4 weeks for $M$. subdolum/M. claviformis and 6 weeks for Levinseniella sp. (Galaktionov et al., 1997).

For the experiment, sediment was sieved through a $0.5 \mathrm{~mm}$ mesh size and bubbled with nitrogen for $24 \mathrm{~h}$ to remove all macroinvertebrates. Clean seawater ( $\approx 35 \mathrm{psu}$ ) was collected at the mouth of the estuary, diluted with demineralised water (until 20 psu) and stored at $10{ }^{\circ} \mathrm{C}$.

\subsection{Experimental design}

Forty glass jars of 1.51 were used as aquaria. Each contained a sediment layer of $3 \mathrm{~cm}$ depth and 0.651 of brackish water (20 psu). To avoid evaporation, a lid was loosely attached to the jars. They were established in a room at $25{ }^{\circ} \mathrm{C}$, with a $12 \mathrm{~h}$ photoperiod. Aeration was provided during $30 \mathrm{~min}$ at each $4 / 2 \mathrm{~h}$ of light/darkness, to avoid oxygen depletion and disturbing isopods' normal activity. To assure stable environmental conditions, the jars were left undisturbed for 48 h. Then, C. carinata specimens were added, 2 weeks after being collected and acclimated to the experimental conditions.

Twenty jars with experimental animals were established. They consisted of 2 sets of 10 replicates, respectively for non-infected and infected isopods. Since only 197 infected C. carinata were found, these determined the abundance to be used. Corresponding to a density of 2680 to 2822 individuals per $\mathrm{m}^{2}$, comparable to the natural population in the estuary during the same period of the year (Ferreira et al., 2004), 7 jars of each set contained 20 specimens and 3 were left with 19. To avoid injuring the isopods and ensure equal size distribution within the infected and non-infected populations, isopods were matched pairwise according to their body length. The initial size of the two coexisting cohorts in both experimental populations was determined through size-frequency distribution analysis of $C$. carinata collected from the Mondego estuary, in the same period of the year (Ferreira et al., 2004). This analysis was performed by ANAMOD software, which is based on the probability paper method (Cassie, 1954). After 45 days, the cephalic lengths of all living $C$. carinata were measured, using photographs taken with a digital video camera mounted on a stereomicroscope. The size of the isopods after 45 days was also analysed in accordance with the natural population structure (Ferreira et al., 2004).

During the experiment, $C$. carinata specimens were regularly fed with frozen Hediste diversicolor. Periodically, the aquaria were disassembled to track the population development (counting and recognising males, non-reproductive and ovigerous females by their relative size, plus the cysts within infected specimens). It was done only 8 times in total to minimise disturbances. The 20 spare jars were used to replace the disassembled ones, which were left undisturbed until the next inspection, under the same temperature and light conditions.

All ovigerous females found were isolated in 25 $\mathrm{cm}^{2}$ cell culture flasks. Environmental conditions were exactly the same as in the experiment, except for the sediment. A layer of fine sand (SDS sand Fontainebleau, ref. 1960027, 99.8\% $\mathrm{SiO}_{2}$, granulometry of 150-300 ppm) was used instead of mud. Generally, cyathurans are not very specific about the sediment in which they live (Burbanck and Burbanck, 1979). This procedure was necessary for counting and following the embryonic development of offspring. Embryos were classified in 3 developmental stages, according to literature (Jazdzewski, 1969; Bamber, 1985; Ferreira et al., 2004).

\subsection{Data analysis}

Statistical analyses were performed using the MINITAB 10.2 software package. All data were inspected for violation of required assumptions and, if so, proper transformations or non-parametric tests were used (Zar, 1996).

\section{Results}

Infected C. carinata hosted 1 to 19 microphallid cysts $(4.2 \pm 0.2$, mean \pm S.E.). Among these, Levinseniella sp. was more abundant $(2.4 \pm 0.2$ cysts, mean\pm S.E.) than $M$. subdolum/M. claviformis $(1.8 \pm 0.2$ cysts, mean \pm S.E.). Infected females $(2.9 \pm 0.4$, mean\pm S.E.) accommodated significantly more cysts of Levinseniella sp. (Wilcoxon's two-sample test: $W=1965, p<0.05)$ than males $(1.8 \pm 0.2$, mean \pm S.E. $)$. 
The cysts were located within the pereon region of the isopods, most of them ( $>50 \%)$ being concentrated in the 4 th and 5 th segments (Fig. 1).

The experiment was divided in 3 periods: (1) before, (2) during, and (3) after the appearance of ovigerous females, in accordance with their removal to individual culture flasks as they came along. The pattern of the mean daily mortality rates differed between these periods (Fig. 2). The first period can be considered as a reference value for the background mortality. For both non-infected and infected isopods, mortality increased gradually until half of the second period. High rates were observed between the 22nd and 27 th days, when ovigerous females were found more frequently. Then, the mortality of the noninfected $C$. carinata declined and remained at a lower level during the third period, close to the initial reference value (Fig. 2A). Contrarily, the infected isopods maintained high rates until the end of the experiment (Fig. 2B). Overall, significantly more infected $(73 \%)$ than non-infected (44\%) specimens died during the whole experimental period ( $t$-test: $\left.t_{18}=-5.33, p<0.001\right)$. Females exhibited higher mortality rates than males, both within the non-infected (Wilcoxon's two-sample test: $W=145, p<0.001$; Fig. 2A) and infected $C$. carinata ( $t$-test: $t_{18}=11.94$, $p<0.001$; Fig. 2B). After the appearance of the last ovigerous female (third period), the half-life time estimated for the non-infected females (74 days) was higher than for the infected ones (20 days). Both were
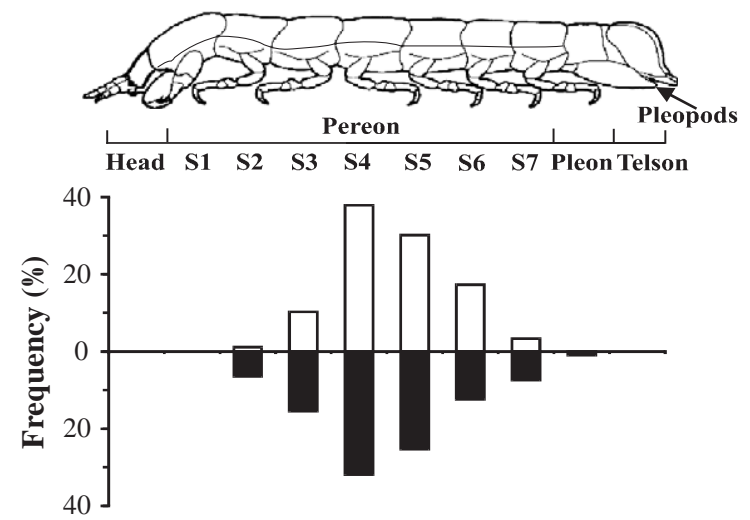

Fig. 1. Location of Levinseniella sp. $(\square, N=309)$ and $M$. subdolum/ $M$. claviformis $(\square, N=236)$ cysts within the body of $C$. carinata ( $N=131$, specimens alive after the 37 th day, when the larger cysts were mature and in a fixed position).

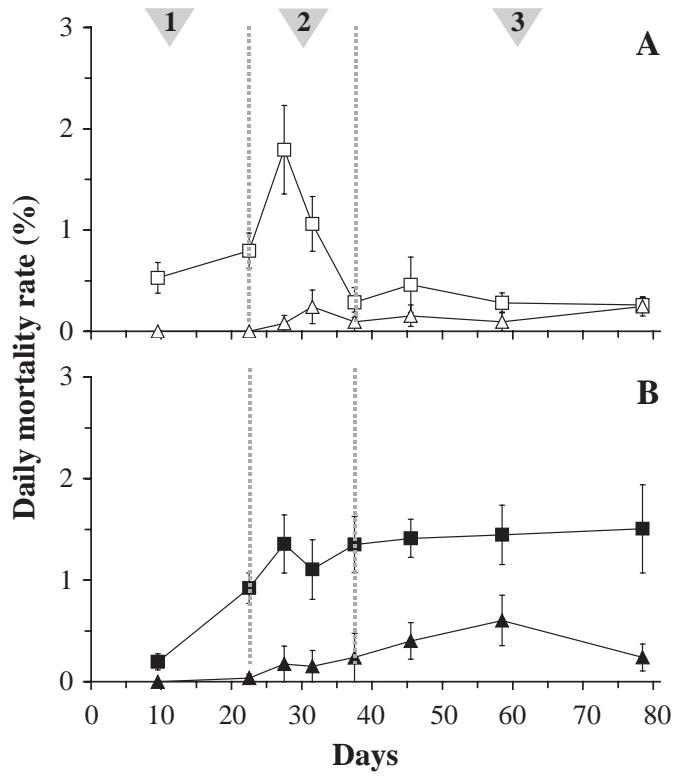

Fig. 2. Comparison of daily mortality rates between: (A) males $(\triangle)$ and females $(\square)$ within the non-infected isopods and between (B) males $(\boldsymbol{\Delta})$ and females $(\mathbf{\square})$ within the infected $C$. carinata. The results express the proportion (\%) of individuals that died per day, between two consecutive examination dates, represented by the mean $( \pm$ S.E. $)$ of all the replicates.

much lower than the half-life of non-infected (280 days) and infected (161 days) males.

Microphallid's influence on the mortality rates of parasitised C. carinata was analysed from the second period onwards, when all cysts were already visible. No differences were found between the initial and final numbers of isopods infected with both groups of trematode species, or just with Levinseniella sp. or $M$. subdolum/M. claviformis (Chi-square test: $\chi_{2}^{2}=0.325$, $p>0.05$ ). Neither was there any selective mortality in relation to isopods infected with 1,2 , and 3 or more cysts (Chi-square test: $\chi_{3}^{2}=1.576, p>0.05$ for Levinseniella sp.; $\chi_{3}^{2}=1.015, p>0.05$ for $M$. subdolum $/ M$. claviformis).

In the non-infected population, almost all males became distinct from females between the 9th and the 22nd days (Fig. 3A), giving a sex ratio of approximately 1:2 (Fig. 3B). In the infected population, this ratio was initially lower (1:8, Fig. 3B) and new males kept on differentiating from females throughout the whole experimental period (Fig. 3A). Afterwards, both sex ratios increased gradually (Fig. 3B), mostly due to the higher mortality rates of females. 


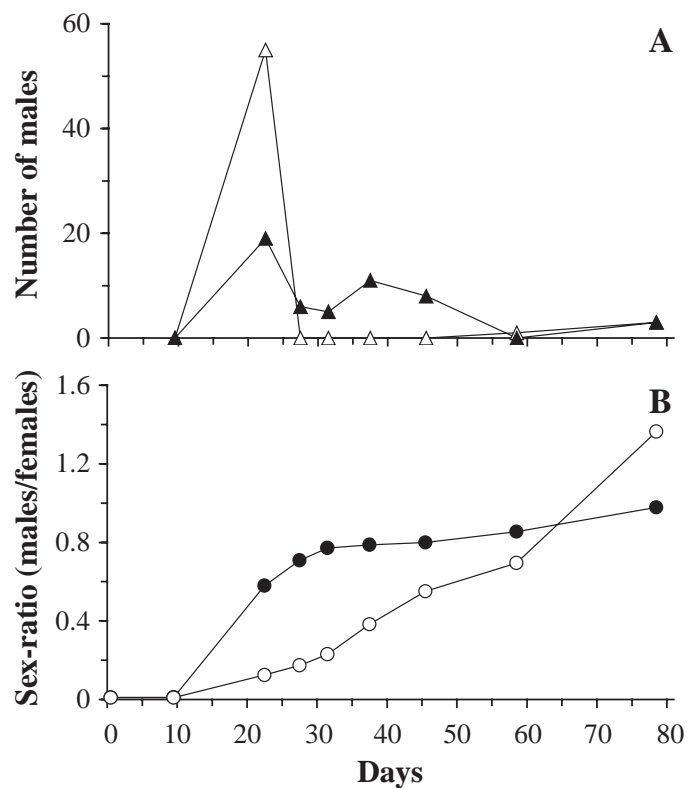

Fig. 3. (A) Number of new males that differentiated from females within the non-infected $(\Delta)$ and infected $(\Delta) C$. carinata populations. Body length plus the number and type of cysts allowed recognising and tracking these individuals during the experiment. (B) Sex ratio within both non-infected $(O)$ and infected populations.

A similar size composition was given at the beginning of the experiment, as infected and noninfected isopods were matched pairwise according to their body length. However, after 45 days, the infected isopods of the 1-year-old cohort were significantly smaller than the non-infected, both for males and females (Table 1). From the 2-year-old cohort, there were no infected males and very few infected females. Either infected $C$. carinata grew significantly less than the non-infected or there was a differential sizeselective mortality between the two groups. No
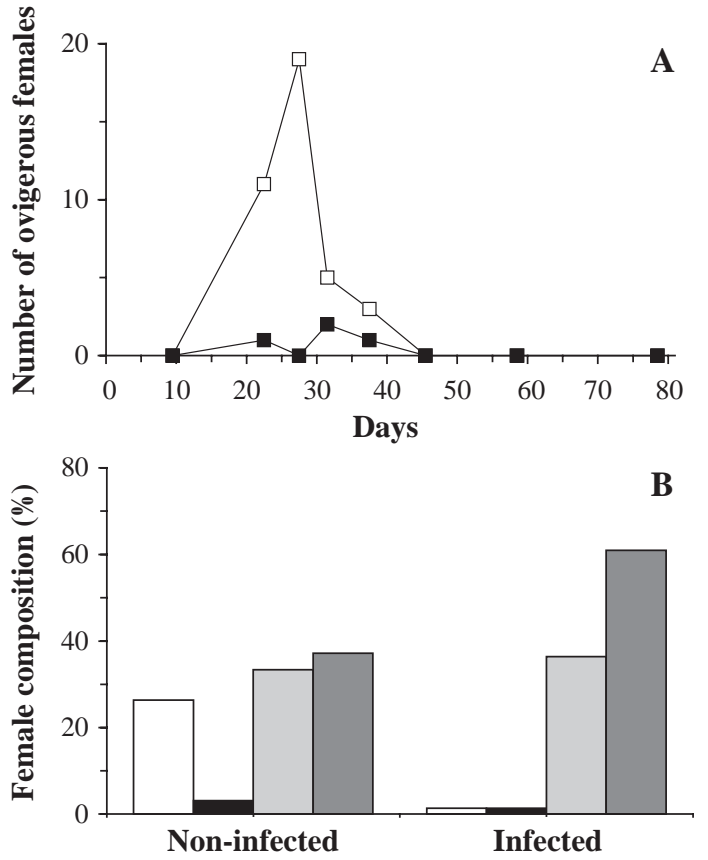

Fig. 4. (A) Number of new ovigerous females within the noninfected ( $\square$ ) and infected ( $\square$ ) C. carinata throughout the experimental period. (B) Female composition within the noninfected and infected isopods ( $\square-$ surviving ovigerous females, - - dead ovigerous females, —-surviving non-reproductive females and $\square$-dead non-reproductive females).

significant correlations existed between C. carinata's size (males and females) and the number of cysts, considering all microphallid groups $\left(r_{41}=0.203\right.$ and $\left.r_{63}=-0.008, p>0.05\right)$, or just Levinseniella $\mathrm{sp}$. $\left(r_{41}=-0.031\right.$ and $\left.r_{60}=-0.067, p>0.05\right)$, or females infected with M. subdolum/M. claviformis $\left(r_{24}=0.109\right.$, $p>0.05)$. There was a significant correlation between males' size and the number of $M$. subdolum $/ M$. claviformis cysts $\left(r_{21}=0.583, p<0.05\right)$.

Table 1

Comparison of mean cephalic lengths $( \pm \mathrm{SD})$ of experimental non-infected and infected $C$. carinata males and females $(N$-sample size). The initial length of all isopods is indicated, as it was not possible to differentiate between males and females at the beginning of the experiment. The population structure was composed by two cohorts: the $1\left(0^{+}\right)$and $2\left(1^{+}\right)$year-old cohorts

\begin{tabular}{|c|c|c|c|c|c|c|c|c|}
\hline \multicolumn{2}{|c|}{ Cephalic length (mm) } & \multicolumn{2}{|l|}{ Initial } & \multicolumn{4}{|l|}{ After 45 days } & \multirow[b]{2}{*}{$t$-test } \\
\hline Cohort & Sex & 1. All & $N$ & 2. Non-infected & $N$ & 3. Infected & $N$ & \\
\hline \multirow[t]{2}{*}{$\overline{0^{+}}$} & Males & $0.41 \pm 0.07$ & 447 & $0.81 \pm 0.10$ & 46 & $0.73 \pm 0.11$ & 43 & $t_{87}=3.32, p<0.01 ; \mu_{1} \neq \mu_{2}$ \\
\hline & Females & & & $0.71 \pm 0.07$ & 51 & $0.65 \pm 0.08$ & 62 & $t_{111}=4.95, p<0.01 ; \mu_{1} \neq \mu_{2}$ \\
\hline \multirow[t]{2}{*}{$1^{+}$} & Males & $0.76 \pm 0.12$ & 26 & $1.13 \pm 0.10$ & 16 & - & 0 & - \\
\hline & Females & & & $0.87 \pm 0.04$ & 10 & $0.89 \pm 0.06$ & 3 & - \\
\hline
\end{tabular}


Ovigerous females appeared during 2 weeks, starting from the 22nd day. A higher frequency was observed until the 27th day (Fig. 4A). From all females within the control population, $29 \%$ produced embryos, $3 \%$ of which died (Fig. 4B). This was higher than the $2 \%$ of ovigerous females registered among the infected isopods (Chi-square test: $\chi_{1}^{2}=28.124$, $p<0.001$ ), half of which died as well. The digenean intensity within these females was rather low and varied between 1 and 2 cysts. The only one with $7 \mathrm{M}$. subdolum/M. claviformis cysts died. The embryonic development period lasted $28 \pm 2$ days (mean \pm S.D.). Each of the 3 considered developmental stages endured similar time intervals, between 8 and 10 days. The last one was more variable because it depended on the reliability of juveniles to live the females' brood pouches. A linear regression was established between the females' cephalic length and their offsprings (number of embryos $=81.2 \times$ female's cephalic length-29.9; $R^{2}=39 \%, N=46$ ). The few infected ovigerous females that did survive contained a number of embryos within the confidence limits $(5 \%)$ of the estimated equation.

\section{Discussion}

Initially, the mortality rates of both infected and non-infected C. carinata were low. Previous experiments have also shown that $C$. carinata is not affected by low infection levels on a short-term time scale (Ferreira et al., in press). Mortality rates increased during the second period, when males and ovigerous females were found among both infected and noninfected C. carinata. This suggests that some individuals may be less fit to cope with the demanding physiological processes taking place during reproduction (e.g. sex reversal and egg production). An idea reinforced by the fact that the non-infected females returned to the background mortality rates afterwards. Moreover, the low rates observed among males suggest that these are the most robust specimens. The isolation of ovigerous females in individual containers cannot explain the mortality differences between the infected and non-infected isopods. In fact, during the third period, the mortality rates of the ovigerous females were similar to those of the noninfected females remaining in the experimental jars.
C. carinata's growth was also affected by the presence of microphallid cysts, as reported before in amphipods (Muus, 1967; Thomas et al., 1995, 1996a,b). After 45 days under experimental conditions, infected $C$. carinata males and females were significantly smaller than the non-infected. Sizeselective mortality is an alternative explanation to the growth differences. However, there was no obvious sign that it happened. All specimens were counted, sexed, and identified by their relative size each time they were inspected. Concerning the infected isopods, it was easy to follow each individual by the number and location of cysts. A higher mortality among larger infected individuals accommodating more cysts was not observed.

C. carinata males can develop by two different ways: (1) sexual maturity of the 1-year-old individuals, or (2) sex reversal of the 2-year-old females (protogynous hermaphroditism). Both processes occurred during the same time interval in the control population. Almost all non-infected males were identified at the 22nd day, resulting in a sex ratio of nearly 0.5 (or 1:2). Among the infected isopods, new males continued to appear until the end of the experiment, although some were able to differentiate at the same time as the non-infected ones. The initial sex ratio of the infected isopods was significantly lower $(0.125$ or $1: 8)$. This may be explained by the longer time required for the 1-year-old individuals to achieve sexual maturity, as a consequence of lower growth rates caused by microphallid cysts. The timing of appearance of these males can perhaps be related to the background of their infection, namely for how long they had been infected and the intensity of their infection. No 2-year-old infected males were observed, so there was no sex reversal of infected females.

C. carinata were able to breed under the present experimental conditions. They produced offspring $11 / 2$ month earlier than under natural conditions (Ferreira et al., 2004), probably stimulated by the high temperature and photoperiod used during the experiment (Jazdzewski, 1969; Bamber, 1985). The embryonic development was also shorter than 45 days estimated from field observations (Ferreira et al., 2004). Microphallids had a negative influence on $C$. carinata's reproduction. Almost no infected females were able to produce embryos. The few specimens 
that did manage to accomplish it and survive ( $1 \%$ of the total population) contained a low abundance of cysts. The fact that females were slightly more infected with Levinseniella sp. than males could potentially contribute to their higher mortality rates. Still, they showed the same pattern as the non-infected females. The mortality rates increase during the second period, probably also as a consequence of a reproduction effort. A possible interpretation could be that these females do try to reproduce, but somehow microphallids have a negative impact on their capability to produce offspring. That attempt could also be related with the age of their infection, since parasite trematodes affect the growth rates of crustaceans, according to the results of this experiment and of other similar works (Muus, 1967; Thomas et al., 1995, 1996a,b). For instance, those that acquired microphallid cysts close to reproduction would be able to breed at the same time as the non-infected females. However, those that had been infected for longer time would achieve a later sexual maturity and develop reproduction mechanisms at different moments in time, during and after the second period. This might explain why they kept higher mean daily mortality rates during the third period, while the noninfected returned to the initial values.

All surviving specimens were kept under surveillance, after the experiment ended. No more ovigerous females were found until the death of the last individual, 6 months after the experimental setup. Notably, $43.5 \%$ of all the ovigerous females died within 1 month after releasing their offspring, which sustains that reproduction is a physically demanding process. These results do also corroborate the strong post-reproduction mortality observed in southern European populations, where only $10 \%$ to $20 \%$ of the 1-year-old individuals are able to survive, after the reproduction peak, and thus accomplish 2 years of life span (Amanieu, 1969; Ferreira et al., 2004).

Fecundity and growth reduction in invertebrates hosting macroparasites has previously been reported among crustaceans, insects, and others (Muus, 1967; Ward, 1986; Thomas et al., 1995, 1996a,b; Hurd and Webb, 1997; Bollache et al., 2002). In the present case few cysts were responsible for the effects observed. Therefore, nutrient competition between host and parasite does not seem to be the most plausible explanation, although it may be an important one. The uptake of nutrients (Ginetsinskaya, 1988; Galaktionov et al., 1996) by microphallids may interfere with the host's allocation of resources to growth and reproduction. However, the way by which microphallids interfered with $C$. carinata's reproduction remains unclear, although several possibilities can be presented. (1) Since moulting is a prerequisite for egg fertilization and oviposition, ecdysial problems (Muus, 1967) and reduced moulting frequency caused by parasites (Thomas et al., 1996a,b) may result in infertility. (2) Mechanical damages inflicted by the presence of parasites in the host's body may also have a negative impact on reproduction. C. carinata eggs are deposited in a marsupium, made up of overlapping oostegites on the $3 \mathrm{rd}, 4 \mathrm{th}$, and 5 th thoracic segments (Burbanck and Burbanck, 1979). The ovaries are located in the same region, with the oviducts emerging in the internal side of the 5th pair of pereopods. The incidence of microphallid cysts in this area may interfere, either mechanically or chemically, with gametogenesis and egg development. In particular, the larger Levinseniella sp. cysts may be more harmful, as they occupy almost all the body cavity of the host. (3) If males or females normal behaviour is altered, then their mating success may be reduced. (4) Parasites may also inhibit oocyte maturation or cause other gametogenesis disorders (Hurd and Webb, 1997) through their impact on the host's hormonal system. Studies across several host-parasite complexes (all with insects as hosts) have shown that parasite induced fecundity reduction is associated with a lower vitellin protein content (yolk) of the host ovaries (Hurd and Webb, 1997). Furthermore, it has been revealed that vitellogenin synthesis and secretion in fat bodies, plus the ability of the ovaries to uptake it from hemolymph (ovarian patency) are markedly reduced, as well as the binding capacity of juvenile hormone, responsible for the regulation of these processes (Hurd and Webb, 1997). Considering that crustaceans share similarities with insects, it is likely that digenean cysts may also mediate their effects through an impact on the crustacean host endocrine system. However, further studies are needed to understand the ways by which trematodes interfere with the metabolism of crustaceans.

Irrespective of the mechanisms involved, the present work shows that microphallid cysts may have severe impact on $C$. carinata populations. It is 
demonstrated that parasites might be a significant mortality agent. Yet, the negative impact on reproduction may be even more severe to such a species with direct development, limiting its dispersal ability. Although $C$. carinata is one of the most important species of the Mondego Estuary intertidal mudflats (Ferreira et al., 2004), it exhibits fluctuating densities in areas where adult mud snails potentially hosting microphallids are abundant (Jensen et al., 2004). Based on the results obtained, this work supports the idea that microphallids can be one of the factors contributing to host fluctuations, causing mortality and recruitment failure. The persistence of local C. carinata populations, co-occurring with dense stocks of mud snails, may depend on the continued appearance of dispersing specimens from elsewhere. As prevalence of microphallids also exhibits interannual fluctuations, perhaps related to the phenology of waders, their impact on the isopods will also vary accordingly. Generally, parasites may contribute to population fragmentation and limitation of the efficient population size. Therefore, knowledge of the parasite fauna is required to understand spatial distribution and dynamics of $C$. carinata and should be considered in future studies.

\section{Acknowledgments}

This paper was supported by a grant from the FCT (Portuguese Foundation for Science and Technology) conceded to S. M. Ferreira (SFRH/BD/5392/2001). The authors are grateful to all colleagues from IMARCoimbra. Support from the Carlsberg Foundation to $\mathrm{K}$.T. Jensen is also acknowledged. [SS]

\section{References}

Amanieu, M., 1969. Variations saisonières de la taille et cycle reproducteur à Arcachon de Cyathura carinata (Krøyer). J. Exp. Mar. Biol. Ecol. 4, 79-89.

Bamber, R.N., 1985. The autoecology of Cyathura carinata (Crustacea: Isopoda) in a cooling water discharge lagoon. J. Mar. Biol. Assoc. UK 65, 181-194.

Bollache, L., Rigaud, T., Cézilly, F., 2002. Effects of two acantocephalan parasites on the fecundity and pairing status of female Gammarus pulex (Crustacea: Amphipoda). J. Invertebr. Pathol. 79, 102-110.
Burbanck, W.D., Burbanck, M.P., 1979. Cyathura (Arthropoda: Crustacea: Isopoda: Anthuridae). In: Hart Jr., C.W., Fuller, S.L.H. (Eds.), Pollution Ecology of Estuarine Invertebrates. Academic Press, New York, pp. 293-323.

Cassie, R.M., 1954. Some use of probability paper in the analysis of size-frequency distributions. Aust. J. Mar. Freshw. Res. 5, $513-522$.

Combes, C., 2001. Parasitism. The Ecology and Evolution of Intimate Interactions. The University of Chicago Press, Chicago.

Deblock, S., 1980. Inventaire des trématodes larvaires parasites des mollusques Hydrobia (Prosobranchies) dés côtes de France. Parassitologia 22, 1-105.

Ferreira, S.M., Pardal, M.A., Lillebø, A.I., Cardoso, P.G., Marques, J.C., 2004. Population dynamics of Cyathura carinata (Isopoda) in a eutrophic temperate estuary. Estuar. Coast. Shelf Sci. 61, 669-677.

Ferreira, S.M., Jensen, K.T., Pardal, M.A., in press. Infection characteristics of a trematode in an estuarine isopod: influence of substratum. Hydrobiologia.

Galaktionov, K.V., Malkova, I.I., Irwin, S.W.B., Saville, D.H., Maguire, J.G., 1996. Development changes in the tegument of four microphallid metacercariae in their second (crustacean) intermediate hosts. J. Helminthol. 70, 201-210.

Galaktionov, K.V., Malkova, I.I., Irwin, S.W.B., Saville, D.H., Maguire, J.G., 1997. The structure and formation of metacercarial cysts in the trematode family Microphallidae Travassos 1920. J. Helminthol. 71, 13-20.

Ginetsinskaya, T.A., 1988. Trematodes, Their Life Cycles, Biology and Evolution. Amerind Publishing, New Delhi.

Helluy, S., 1984. Relations hôst-parasites du trématode Microphallus papillorobustus (Rankin, 1940): III. Facteurs impliqués dans les modifications du comportement des Gammarus hôtes intermédiaires et tests de prédation. Ann. Parasitol. Hum. Comp. 59 (1), $41-56$.

Hurd, H., Webb, T., 1997. The role of endocrinological versus nutritional influences in mediating reproductive changes in insect hosts and insect vectors. In: Beckage, N.E. (Ed.), Parasites and Pathogens-Effects on Host Hormones and Behaviour. Chapman \& Hall, New York, pp. 179-197.

Jazdzewski, K., 1969. Biology of two hermaphroditic Crustacea, Cyathura carinata (Krøyer) (Isopoda) and Heterotanais oerstedi (Krøyer) (Tanaidacea) in waters of the Polish Baltic Sea. Zool. Pol. 19, 5-25.

Jensen, T., Jensen, K.T., Mouritsen, K.N., 1998. The influence of the trematode Microphallus claviformis on two congeneric intermediate host species (Corophium): infection characteristics and host survival. J. Exp. Mar. Biol. Ecol. 227, 35-48.

Jensen, K.T., Ferreira, S.M., Pardal, M.A., 2004. Trematodes in a Cyathura carinata population from a temperate intertidal estuary: infection patterns and impact on host. J. Mar. Biol. Assoc. UK. 84, 1151-1158.

Meissner, K., Bick, A., 1999. Mortality of Corophium volutator (Amphipoda.) caused by infestation with Maritrema subdolum (Digenea, Microphallidae)—laboratory studies. Dis. Aquat. Org. $35,47-52$.

Mouritsen, K.N., Jensen, K.T., 1997. Parasite transmission between soft-bottom invertebrates: temperature mediated infection rates 
and mortality in Corophium volutator. Mar. Ecol. Prog. Ser. $151,123-134$.

Muus, B.J., 1967. The fauna of Danish estuaries and lagoons. Distribution and ecology of dominating species in the shallow reaches of the mesohaline zone. Medd. Dan. Fisk. Havunders. 5, $1-316$.

Thomas, F., Lambert, A., Meeüs, T., Cézilly, F., Renaud, F., 1995. Influence of Microphallis hoffmanni (Trematoda, Microphallidae) on the survival, sexual selection and fecundity of Gammarus aequicauda (Amphipoda). Can. J. Zool. 73, 1634-1639.

Thomas, F., Renaud, F., Cézilly, F., 1996a. Assortive pairing by parasitic prevalence in Gammarus insensibilis (Amphipoda): patterns and processes. Anim. Behav. 52, 683-690.
Thomas, F., Verneau, O., Santalla, F., Cézilly, F., Renaud, F., 1996b. The influence of infection by a trematode parasite on the reproduction biology of Gammarus insensibilis (Amphipoda). Int. J. Parasitol. 26 (11), 1205-1209.

Ward, P.I., 1986. A comparative field study of the breeding behaviour of a stream and a pond population of Gammarus pulex (Amphipoda). Oikos 46, 29-36.

Zar, J.H., 1996. Biostatistical Analysis. Prentice Hall International, London. 